\title{
Infrasound - the cause of strong Polar Mesosphere Winter Echoes?
}

\author{
S. Kirkwood ${ }^{1}$, P. Chilson ${ }^{2}$, E. Belova ${ }^{1}$, P. Dalin ${ }^{1}$, I. Häggström ${ }^{3}$, M. Rietveld ${ }^{4}$, and W. Singer ${ }^{5}$ \\ ${ }^{1}$ Swedish Institute of Space Physics, Box 812, 98128 Kiruna, Sweden \\ ${ }^{2}$ School of Meteorology, University of Oklahoma, Norman, OK, USA \\ ${ }^{3}$ EISCAT Scientific Association, Kiruna, Sweden \\ ${ }^{4}$ EISCAT Scientific Association, Ramfjordmoen, Norway \\ ${ }^{5}$ Leibniz Institute of Atmospheric Physics, Kühlungsborn, Germany
}

Received: 6 July 2005 - Revised: 18 December 2005 - Accepted: 16 January 2006 - Published: 23 March 2006

\begin{abstract}
The ESRAD 52-MHz and the EISCAT 224-MHz radars in northern Scandinavia observed thin layers of strongly enhanced radar echoes from the mesosphere (Polar Mesosphere Winter Echoes - PMWE) during a solar proton event in November 2004. Using the interferometric capabilities of ESRAD it was found that the scatterers responsible for PMWE show very high horizontal travel speeds, up to $500 \mathrm{~ms}^{-1}$ or more, and high aspect sensitivity, with echo arrival angles spread over as little as $0.3^{\circ}$. ESRAD also detected, on some occasions, discrete scattering regions moving across the field of view with periodicities of a few seconds. The very narrow, vertically directed beam of the more powerful EISCAT radar allowed measurements of the spectral widths of the radar echoes both inside the PMWE and from the background plasma above and below the PMWE. Spectral widths inside the PMWE were found to be indistinguishable from those from the background plasma. We propose that scatter from highly-damped ion-acoustic waves generated by partial reflection of infrasonic waves provides a reasonable explanation of the characteristics of the very strong PMWE reported here.
\end{abstract}

Keywords. Ionosphere (Plasma waves and instabilities) Meteorology and atmospheric dynamics (Middle atmosphere dynamics) - Radio science (Interferometry)

\section{Introduction}

It has been known for several decades that radar echoes can be obtained from the mesosphere by sufficiently powerful radars operating at VHF frequencies. The most powerful radars such as Jicamarca (50 MHz) and EISCAT (224 MHz), built as "incoherent scatter" radars, can detect the extremely weak scatter from thermally-induced fluctuations in the

Correspondence to: S. Kirkwood

(sheila.kirkwood@irf.se) electron gas which permeates the mesosphere and constitutes the D-region, the lowest part of the Earth's ionosphere (see, e.g. Mathews, 1984). Less powerful "coherent" radars such as the 50-MHz Poker Flat radar operating in Alaska between 1979 and 1987, and more recently several radars operating close to $50 \mathrm{MHz}$ in northern Scandinavia, have observed scatter from relatively narrow layered structures in the mesosphere. For example, Balsley et al., 1983, reported a climatology of mesospheric radar echoes, with the strongest echoes appearing in the upper mesosphere in summer and somewhat weaker echoes appearing in the lower mesosphere in winter. Layers of enhanced radar echoes were often observed to descend with time and they were interpreted as the signatures of turbulence, caused by gravity wave break down or by wind-shear-induced instabilities at particular phases of large-scale atmospheric waves or tides. Note that atmospheric radar echoes generally require fluctuations in the refractive index for radio waves with scale-sizes matching half the radar wavelength, corresponding to $3 \mathrm{~m}$ for $50-\mathrm{MHz}$ radars and $67 \mathrm{~cm}$ for a 224-MHz radar. At mesospheric heights, refractive index fluctuations due to fluctuations in electron density dominate those which, in theory, could be due to neutral temperature, density or humidity fluctuations. Turbulent fluctuations in neutral density are expected at scale sizes of a few meters or more and these can be expected to lead to similar fluctuations in ion and electron density, at least during daylight or in the upper mesosphere, and so provide at least a qualitatively possible explanation for the observed radar echoes (Hill, 1978). However, it was not expected that turbulent structures would be present in the electron density in the upper mesosphere at shorter scale sizes than a few meters, due to rapid damping by the high viscosity prevailing at those heights (see, e.g. Thrane and Grandal, 1981). The EISCAT 224-MHz VHF radar (Table 1) started operations in 1986 and made the surprising observation of extremely strong radar echoes from thin layers at heights close to the summer mesopause $(80-90 \mathrm{~km})$. As mentioned above, the

Published by Copernicus GmbH on behalf of the European Geosciences Union. 
Poker Flat MST radar (Bragg scale $\sim 3 \mathrm{~m}$ ) had earlier observed echoes from the same height region and they had been thought to be due to turbulence (Balsley, 1983) . However, it became clear that the echoes observed by EISCAT could not reasonably be explained by turbulence alone since turbulent eddies at the scale size needed to cause EISCAT echoes $(67 \mathrm{~cm})$ should be strongly damped - they should not be able to produce such strong echoes as observed by the radar. The physics behind these "Polar Mesosphere Summer Echoes" (PMSE) has since been the subject of a very large number of scientific studies both by radars and by sounding rockets, and it is nowadays considered well-proven that layers of charged aerosol particles are responsible for their existence since these hinder the viscous damping of small-scale structure in the electron gas (Kelley et al., 1987; Cho and Röttger, 1997; Rapp and Luebken, 2004). Since it is well known that ice-clouds (noctilucent clouds) form at the high-latitude summer mesopause, it is not unreasonable to propose that the same particles, or smaller ice-particles, can be responsible for PMSE.

During recent years, the relatively low-power $52-\mathrm{MHz}$ ESRAD radar (Table 1), sometimes simultaneously with the EISCAT VHF radar, has observed surprisingly strong radar echoes from the winter mesosphere during solar proton events and on other occasions when electron densities at mesospheric heights are enhanced by energetic particle precipitation (Kirkwood et al., 2002a, 2002b, 2005; Belova et al., 2005). At $52 \mathrm{MHz}$, the echoes are highly aspect sensitive and are much stronger than the mesospheric radar echoes earlier reported from lower latitudes or from winter high latitudes (see a comparison in Kirkwood et al., 2005, and references therein). Kirkwood et al. (2002a), named the echoes "Polar Mesosphere Winter Echoes" (PMWE), to emphasise the similarities with PMSE, i.e. unexpectedly strong echo power and a clear connection to the polar regions (in the case of PMWE, through their relationship to the energetic particle precipitation which is characteristic for the polar regions). Volume reflectivities measured by ESRAD in PMWE are typically $10^{-16}-10^{-13} \dot{\mathrm{m}}^{-1}$, which can be compared to $10^{-16}-10^{-10} \mathrm{~m}^{-1}$ for the summer echoes, PMSE (for the same radar). In other words, PMWE are as strong as the weaker half of PMSE (Kirkwood et al., 2005).

As in the case of summer echoes, these winter echoes have many characteristics which do not agree well with the idea that they are due to turbulence. Of particular relevance in this context is the new information on atmospheric turbulence which was gathered in the late 1980's and 1990's, by a large number of sounding rocket measurements in the highlatitude winter mesosphere (Luebken et al., 1993). These generally found much lower turbulence levels than had been assumed when radar echoes were initially interpreted in terms of turbulence. More specifically, quantitative analysis of recent PMWE observations by ESRAD and EISCAT has shown that they seem to be too strong to be explained by even the strongest turbulence found in the sounding-rocket measurements (Kirkwood et al., 2005; Stebel et al., 2004; Belova et al., 2005). It has also been found that PMWE appear at heights where co-located meteorological rockets show a stable atmosphere - i.e. where there is no reason to expect turbulence at all (Kirkwood et al., 2005). However, there are many uncertainties associated with calculating expected radar volume reflectivities from turbulence levels, and with the limited height resolution of meteorological rocket measurements, so that those results cannot be considered conclusive. Also, PMWE can be observed on occasion descending slowly through the atmosphere clearly following the phase of background inertio-gravity waves (Belova et al., 2005). This suggests dynamic control of the PMWE or, at least, of the altitude where they appear.

Lidar observations consistent with the possibility that aerosol particles might be involved in creating PMWE, as they are in PMSE, have been reported by Kirkwood et al. (2002b), Stebel et al. (2004). However, the winter mesosphere is much too warm and dry for ice-clouds to form so there is no obvious source of such particles. "Dust" or "smoke" from meteor ablation (Hunten et al., 1981) is a possible source but it is not clear that this can provide sufficient numbers of particles (Stebel et al., 2004). The lidar observations do not provide conclusive evidence of aerosol particle layers associated with PMWE. The PMWE-related anomalies in the lidar backscatter profiles can also be interpreted as "inversions" in the temperature profile, where the temperature first decreases sharply with increasing height and then increases again. With this interpretation of the lidar observations, the PMWE appear in the upper part of the inversion structure where the temperature is increasing with height. Even in this case, turbulence does not appear a likely explanation as it would rather be expected in the lower part of the inversion structure (Stebel et al., 2004).

Previous published observations of PMWE have discussed their strength and their relation to background winds, atmospheric stability, and possible aerosol particles. Here we take another approach. We use recent technological advances at ESRAD (particularly in available time resolution) together with the radar's interferometric capabilities, to study in detail the nature of the PMWE themselves. This allows us to examine, for example, the speed at which areas of enhanced radar scatter move across the antenna array, the direction in which they move and whether they are diffuse or specular in their scattering characteristics. We also use simultaneous observations of the spectrum of the scattered signal from both the background ionosphere and the PMWE layer by the EISCAT VHF radar. These allow us to compare the dispersion characteristics of the two types of scatter signal. Finally, we use wind measurements from the Andenes MF radar to compare the morphology of the PMWE and the horizontal drifts of PMWE scatterers with background winds. 


\section{Observations}

As reported by Kirkwood et al. (2002a), PMWE are often observed during solar proton events, most likely because these can provide a strong and persistent ionising source for the appropriate region of the atmosphere over periods of many hours. One such event started on 8 November 2004 and persisted until 16 November 2004. Both the EISCAT VHF radar and the ESRAD radar observed intermittent PMWE throughout the period. The most intense PMWE were observed by ESRAD on the evening of 10 November. Figure 1 gives an overview of the radar measurements for the whole day, and Figs. 2-13 give more detailed analyses of the periods when PMWE were observed.

A possible reason why the PMWE were stronger on the evening of 10 November than at other times during the solar proton event is that the background electron densities were slightly higher than those at PMWE heights at other times (see, e.g. Fig. 1). Enhanced electron densities at these heights are due to the combined effects of the solar protons and energetic electrons from within the magnetosphere. The latter source varies widely during the course of the solar proton event. In this paper we are not primarily concerned with the causes of variations in the echo power but rather in the spatial and spectral fine-structure of the radar echoes so we choose to study the 10 November because the strength of the echoes allows us to do this as accurately as possible.

\subsection{Alomar MF radar}

The Alomar MF $(1.98 \mathrm{MHz})$ radar, is located on the island of Andøya, in Arctic Norway $\left(69.17^{\circ} \mathrm{N}, 16.01^{\circ} \mathrm{E}\right)$, about $250 \mathrm{~km} \mathrm{NW}$ of ESRAD, $120 \mathrm{~km} \mathrm{SW}$ of EISCAT. The system provides continuous horizontal winds in spaced antenna mode using full correlation analysis (Briggs, 1985). Hourly mean winds are formed from 3-min data samples with a 4$\mathrm{km}$ height resolution, oversampled in steps of $2 \mathrm{~km}$. For more information on this radar see Singer at al., 1997. The lowest panel of Fig. 1 shows zonal winds measured by the radar. Note that attenuation of the signal due to the very high electron densities associated with the solar proton event, makes it impossible to get reliable wind estimates above about 65$70 \mathrm{~km}$ during the hours closest to midday. In the morning sector, the wind speed increases with height and the speed contours show signs of a slow descent over time, suggesting the descending phase of a large-scale wave (such as a tide). The descent rate (ca $1-2 \mathrm{~km} / \mathrm{h}$ ) is comparable with the vertical wavelength of about $35 \mathrm{~km}$ of the 12 -h tide as obtained from the Andenes meteor radar (data not shown), at slightly higher altitude $(82-97 \mathrm{~km})$. The descent rate of the wave phase in Fig. 1 is similar to the descent rate of the EISCAT and ESRAD PMWE in the same time sector (ca. $1 \mathrm{~km} / \mathrm{h}$ ). This is discussed in more detail in Sect. 2. In the evening sector, the winds increase in speed towards the higher altitudes but there is no clear phase progression in the height
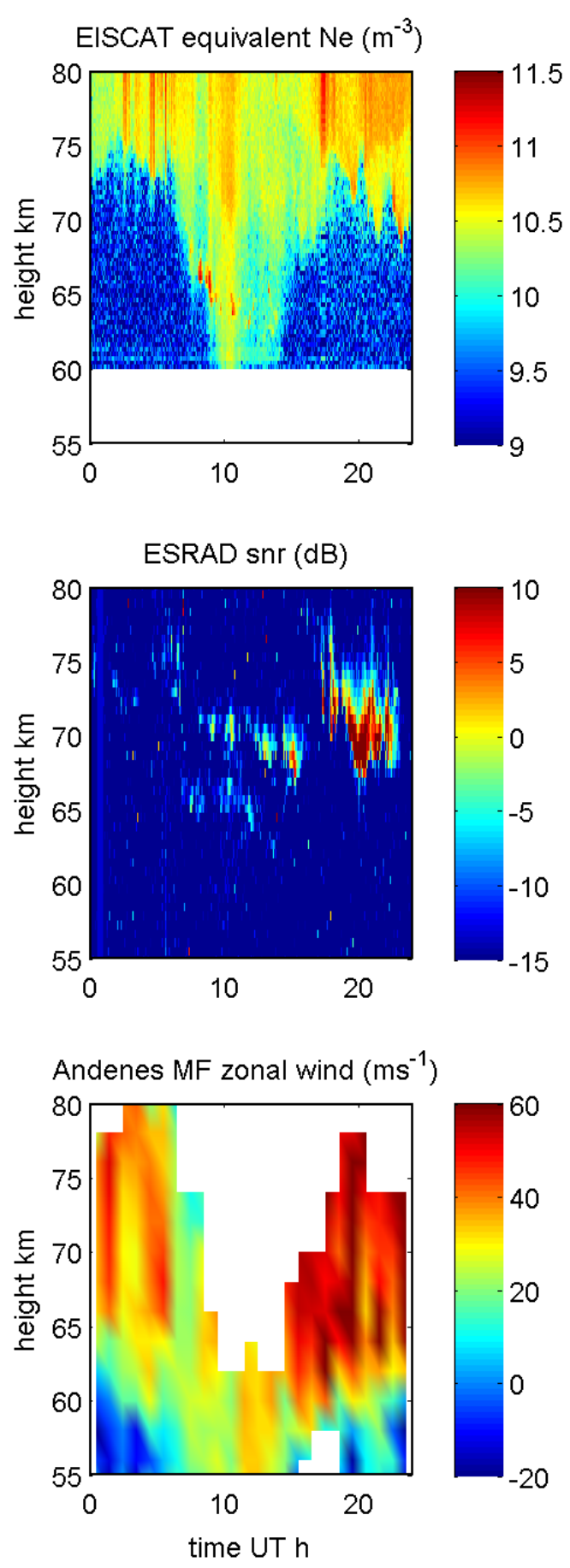

Fig. 1. Overview of observations on 10 November 2004. Upper panel shows equivalent electron densities measured by the EISCAT 224-MHz VHF radar (1-min integrated data), middle panel shows radar echo signal to noise ratio measured by the ESRAD 52-MHz radar $(600-\mathrm{m}$ height resolution, $25 \mathrm{~s}$ average data, one profile each $64 \mathrm{~s}$ ), lower panel shows zonal winds derived from measurements by the Andenes 2-MHz radar (time resolution $1 \mathrm{~h}$, height resolution $4 \mathrm{~km}$, interpolation used for plotting). 
Table 1. ESRAD and EISCAT VHF radar characteristics. Antenna sizes and apertures are given in order (zonal dimension, meridional dimension).

\begin{tabular}{|c|c|c|}
\hline & EISCAT & ESRAD \\
\hline \multirow[t]{2}{*}{ Location } & $69.58 \mathrm{~N}, 19.22 \mathrm{E}$ & $67.89 \mathrm{~N}, 21.08 \mathrm{E}$ \\
\hline & $86 \mathrm{~m}$ above sea level & $295 \mathrm{~m}$ above sea level \\
\hline Antenna area & $4800 \mathrm{~m}^{2}$ & $\sim 4000 \mathrm{~m}^{2}$ \\
\hline $\begin{array}{l}\text { Antenna 3-dB beam width } \\
\text { (whole antenna) }\end{array}$ & $\sim 1.7 \times 0.6 \mathrm{deg}$ & $\sim 2 \times 3 \mathrm{deg}$ \\
\hline Antenna configuration & $\begin{array}{l}4 \text { parabolic cylindrical elements each } \\
30 \times 40 \mathrm{~m} \text {. Steerable between } \\
\text { vertical and } 30^{\circ} \text { elevation towards the } \\
\text { north. } \\
\text { Circular polarisation }\end{array}$ & $\begin{array}{l}18 \times 16 \text { array of } 5 \text {-element yagis } \\
\text { vertical pointing, } \\
\text { plane } \mathrm{N}-\mathrm{S} \text { polarisation } \\
\text { yagi spacing } 4.04 \mathrm{~m} \text { divided into } \\
6 \text { sub-arrays each with } 6 \times 8 \text { yagis }\end{array}$ \\
\hline Transmitter peak power & $2 \times 1500 \mathrm{~kW}$ & $72 \mathrm{~kW}$ \\
\hline Frequency & $222-225 \mathrm{MHz}$ & $52 \mathrm{MHz}$ \\
\hline Number of receivers & 2 & 6 \\
\hline $\begin{array}{l}\text { Typical system noise } \\
\text { (including sky noise) }\end{array}$ & $250-350 \mathrm{~K}$ & $\sim 10000-20000 \mathrm{~K}$ \\
\hline
\end{tabular}

at which this happens. The evening winds are discussed in more detail in Sect. 3.

\subsection{EISCAT}

The EISCAT facility is situated near Troms $\varnothing$, in northern Norway, about $200 \mathrm{~km}$ north of the ESRAD radar. A summary of the relevant characteristics of the EISCAT VHF radar is given in Table 1 . The operation mode used on this occasion is documented in Table 2. Further details of the EISCAT system and the mode of operation can be found in Turunen et al. (2002) and at http://www.eiscat.se.

The uppermost panel of Fig. 1 shows EISCAT measurements of "equivalent electron density", i.e. the electron density which would produce the observed scatter-signal strength if the scatter were due to thermal fluctuations in the electron/ion plasma which is present (assuming no negative ions and equal electron and ion temperatures). Our "equivalent" electron density is calculated in the same way as the "raw" electron density often used by the incoherent-scatter community. We use the term "equivalent" to emphasise the fact that there are echoes present, i.e. PMWE, which are not due to the usual thermal fluctuations. Most of the signals are, as would be expected, from enhanced electron densities caused by precipitating high-energy protons and electrons. The solar protons, in particular, provide a strong ionizing source for the atmosphere throughout the day, penetrating down to $60-\mathrm{km}$ altitude and below. At night, electrons readily become attached, forming negative ions and reducing the number of free electrons - this is seen as reduced electron density in Fig. 1. Superimposed on this "normal" signal are two regions with PMWE - between ca. 62 and $68 \mathrm{~km}$, from 07:00-12:00 UT, and less easily seen in Fig. 1, between ca. 68 and $73 \mathrm{~km}$, from 19:00-24:00 UT. These time/height regions are examined in more detail in the following figures.

The uppermost panel of Fig. 2 shows the EISCAT signal power in $\mathrm{dB}$ (arbitrary reference), during the pre-noon time interval. PMWE are clearly visible as the red areas, 5-10 dB above the background. The slow descent of the PMWE layer is at a similar rate to the descent of the wind pattern seen by the MF radar in the lowest panel of Fig. 1 (ca. $1 \mathrm{~km}$ per hour). Because of attenuation caused by the high electron densities, MF winds are not available at exactly the times and heights when the PMWE was seen. The winds immediately before the PMWE appearance are available but do not show any distinct structures at the height of the PMWE. This is likely a problem of resolution. A previous study of the relationship between PMWE and winds (Belova et al., 2005) showed very close correlation between a slowly descending PMWE in the daytime sector and a strong wave in the horizontal winds with a vertical wavelength of only $5 \mathrm{~km}$. Unfortunately the MF radar cannot resolve the wind profile on such small height scales.

The second panel of Fig. 2 shows the Doppler shift of the radar echo, in units corresponding to the rate at which the radar-scatterers are (on average) approaching (positive) or receding from the radar. Since the radar antenna was directed vertically on this occasion, and the antenna beam is rather narrow, the Doppler should correspond mainly to 
Table 2. Radar operating modes 10 November 2004.

\begin{tabular}{llll}
\hline & $\begin{array}{l}\text { ESRAD } \\
\text { fca_4500 }\end{array}$ & $\begin{array}{l}\text { ESRAD } \\
\text { alias_300 }\end{array}$ & $\begin{array}{l}\text { EISCAT } \\
\text { arc_dlayer.v }\end{array}$ \\
\hline pulse repetition frequency & $1300 \mathrm{~Hz}$ & $2995 \mathrm{~Hz}$ & $741 \mathrm{~Hz}$ \\
\hline pulse length (bit length) & $600 \mathrm{~m}$ & $300 \mathrm{~m}$ & $300 \mathrm{~m}$ \\
\hline no. of bits in code & 8 & 8 & 64 \\
\hline no. of code permutations & 2 & 2 & 128 \\
\hline no. of coherent integrations & 16 & 32 & 1,128 \\
\hline sample time resolution & $24.6 \mathrm{~ms}$ & $21.4 \mathrm{~ms}$ & $5 \mathrm{~s}, 173 \mathrm{~ms}$ \\
\hline no. of post-decoding integrations & 1 & 1 & 28,1 \\
\hline lag resolution & $24.6 \mathrm{~ms}$ & $21.4 \mathrm{~ms}$ & $1.35,173 \mathrm{~ms}$ \\
\hline maximum lag & $25 \mathrm{~s}$ & $22 \mathrm{~s}$ & $0.17,4.8 \mathrm{~s}$ \\
\hline sample time resolution & $24.6 \mathrm{~ms}$ & $21.4 \mathrm{~ms}$ & $5 \mathrm{~s}, 173 \mathrm{~ms}$ \\
\hline no. of sequential samples & $1024 / \mathrm{min}$ & $1024 / \mathrm{min}$ & $12,336 / \mathrm{min}$ \\
\hline no. of receivers used & 5 & 5 & 1 \\
\hline no. of antenna segments used: Tx & 6 & 6 & 2 \\
\hline no. of antenna segments used: Rx & 5 & 5 & 2 \\
\hline
\end{tabular}

vertical movement of the structures in the electron gas responsible for the scatter. Strips of alternating upward and downward movement at speeds up to $10 \mathrm{~ms}^{-1}$ are usually interpreted as caused by neutral air movement associated with gravity waves. The lowermost panel shows the spectral width of the EISCAT radar returns. Outside the PMWE, this is usually considered to be caused by thermal fluctuations in electron density within the scattering volume, due to highly damped ion-acoustic waves (the collision dominated ion-line spectrum, see e.g. Mathews, 1984). There are no distinctive differences in Doppler or spectral widths visible in Fig. 2 associated with the PMWE. Any differences present are clearly small.

Individual spectra below, inside, and above the morning PMWE layer are shown in Fig. 3. These are averages over the interval 08:36-08:42 UT and are typical examples. The lefthand panel shows the signal power as a function of height. The PMWE is seen clearly as increased power between 65$67 \mathrm{~km}$ heights. The right-hand panel shown normalised spectra. The spectra from the PMWE layer show less stochastic noise than the surrounding spectra - this is to be expected since the signal is much stronger. However, there are no particular distinguishing features of the width of the spectra within the PMWE, although there is a slight shift to lower Doppler.

In Fig. 4, Doppler and spectral width inside and outside the PMWE are compared statistically, for the whole height/time interval shown in Fig. 2. Note that the spectral width is the half-power half-width and both Doppler and spectral width are expressed in $\mathrm{ms}^{-1}$, (i.e. $\mathrm{Hz} \times 0.5 \times$ radar wavelength). Here we can see that there is a slight shift to lower Doppler inside the PMWE (power $>45 \mathrm{~dB}$ ). Outside the PMWE, the mean Doppler is zero while inside the PMWE mean Doppler is -2 to $-3 \mathrm{~m} / \mathrm{s}$. There is however, little difference in the spectral widths inside and outside the PMWE - the medians are very close although there is a tail of wider spectra inside the PMWE.

Figure 5 shows similar information to Fig. 2 but now during the late evening time interval. PMWE are visible as the red areas, 5-10 dB above the background, at the lower edge of the green area. They are not as pronounced as in the pre-noon sector. The Doppler shift of the radar echoes, is less well determined in this time interval, partly because of lower signal levels but also because the spectral widths are much broader. The broader spectral widths outside the PMWE (compared to Fig. 2) can be explained partly by the altitude difference between the two examples, and partly by an expected increase of the negative-ion to electron ratio $(\Lambda)$ in the evening hours. In this height region, the width of the ion-line spectrum is expected to increase with increasing $\Lambda$ and with increasing height, the latter approximately as the inverse of the neutral density (Mathews, 1984). These effects on the spectral width are discussed more quantitatively in Sect. 3.1. Here we simply note that, again, there are no 


\section{EISCAT signal power (dB)}
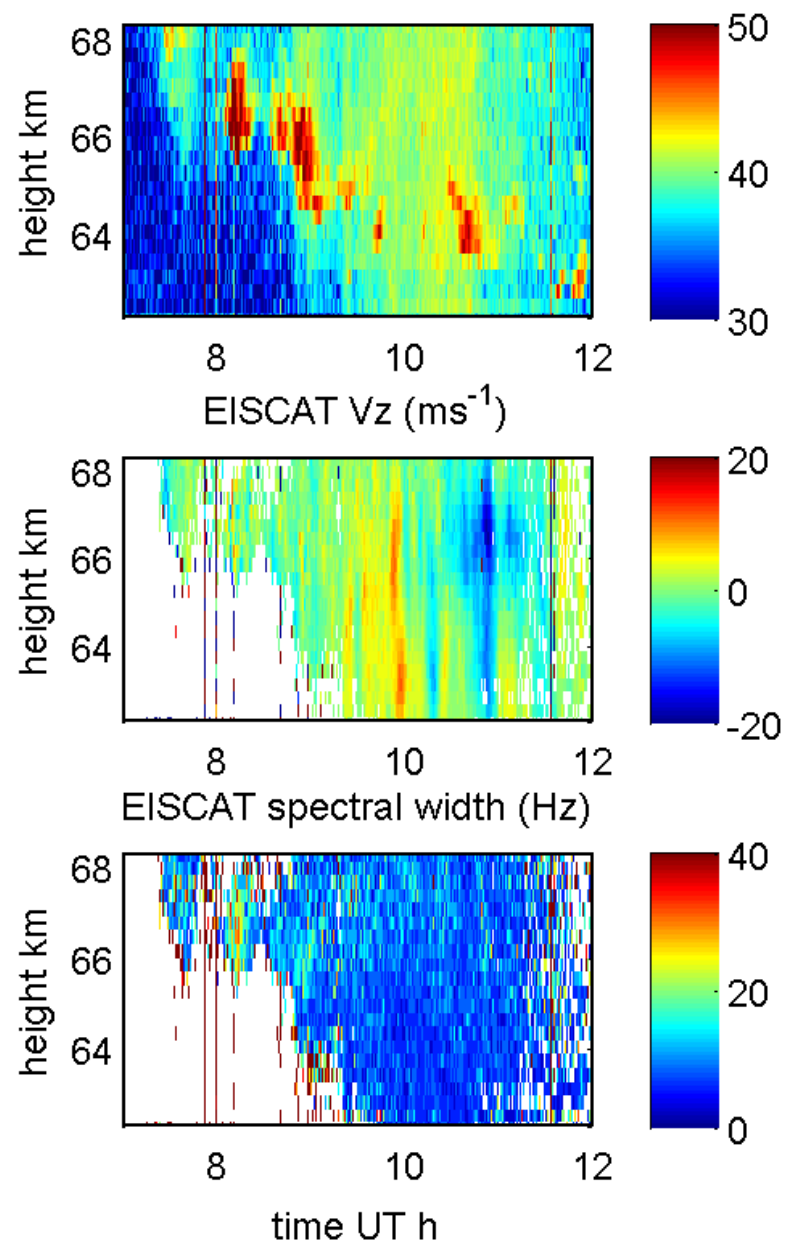

Fig. 2. EISCAT observations covering the strong PMWE event in the pre-noon sector. Upper panel shows radar echo strength, middle panel shows echo Doppler shift (positive towards the radar), lower panel shows echo spectral width (all $30 \mathrm{~s}$ integrated data).

distinctive differences in Doppler or spectral widths visible in the colour panels in Fig. 5, associated with the PMWE.

Individual spectra above, below and within the PMWE layer, averaged over the interval 23:06-23:12 UT, are shown in Fig. 6. Note that, although the total power in the PMWE radar echoes is similar here to the case in Fig. 3, the power is spread over a larger frequency interval so that the power in the centre of the spectrum is less. Since the scale for plotting each spectrum is adjusted to the power in the centre, the spectra appear noisier in this case. Here again the PMWE is seen to involve growth and decay of the scatter over the same spectral region as the background ion-line. Again, there are no particular distinguishing features of the spectral width within the PMWE, compared to the heights above. (Note that any slight difference in Doppler such as in Fig. 3 would be hard to see here since the spectra are noisier and much wider.)
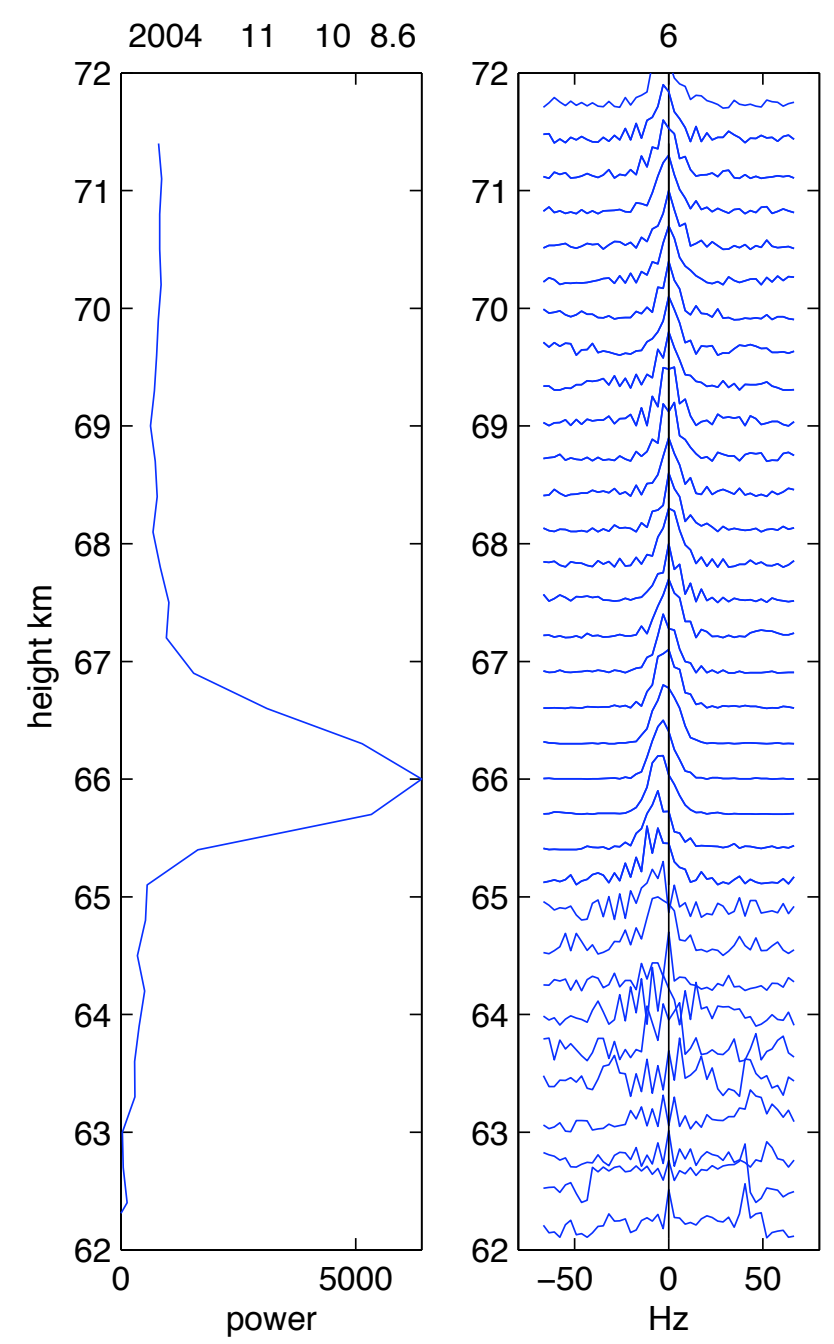

Fig. 3. EISCAT observations averaged 08:36-08:42 UT on 10 November 2004. Left-hand panel shows the height profile of echo power, right-hand panel shows echo spectra, normalised by the echo power.

Figure 7 shows the statistical comparison of Doppler and spectral widths for the whole height/time interval shown in Fig. 5. Here we can see that the distributions of Doppler and spectral widths are rather similar inside and outside the PMWE. There is hint of both lower and higher Doppler offsets and higher median spectral width inside PMWE, but it is doubtful if these are statistically significant. Outside the PMWE, the mean Doppler is again zero while inside the PMWE there are peaks in the distribution at both -2 to $3 \mathrm{~m} / \mathrm{s}$ and +4 to $+5 \mathrm{~m} / \mathrm{s}$. Median spectral width outside the PMWE is $7-9 \mathrm{~m} / \mathrm{s}$, about three times the non-PMWE spectral width in Fig. 4. Inside the PMWE the median spectral width is $9-11 \mathrm{~m} / \mathrm{s}$, but the distributions both inside and outside the PMWE are broad, and there is no clear difference between the distributions outside and inside the PMWE layer. 

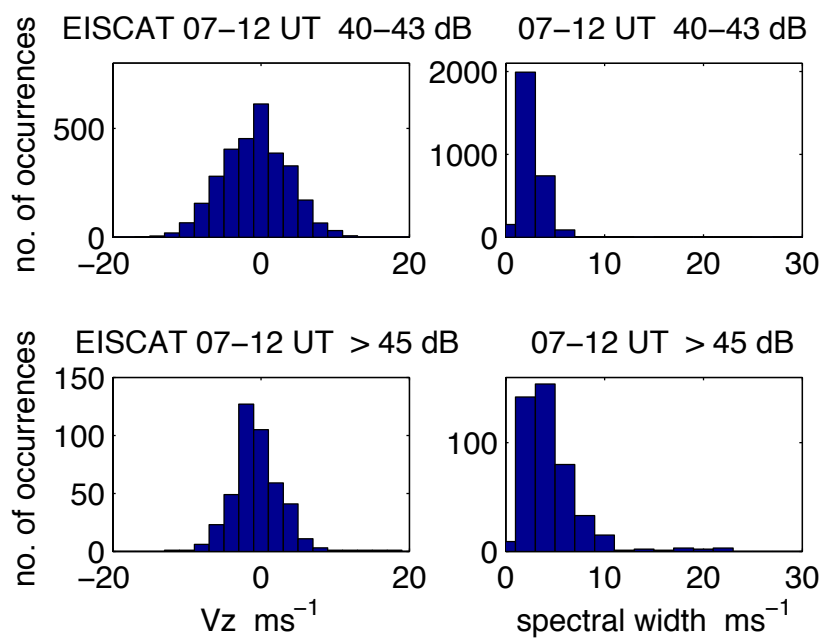

Fig. 4. Histograms showing the distribution of Doppler shifts and spectral widths for the EISCAT observations included in Fig. 2. The power interval $40-43 \mathrm{~dB}$ is chosen to represent echoes from the background ionospheric plasma, while power $>45 \mathrm{~dB}$ is representative of PMWE.

\subsection{ESRAD}

Table 1 lists the main characteristics of the ESRAD radar, and Table 2 describes the particular modes operating on 10 November 2004. Two modes were operated, in alternating time slots of about $30 \mathrm{~s}$ each. The mode "fca_4500" offers 4 times higher signal-to-noise ratio compared to the mode "alias_300", but at the expense of poorer height resolution $(600 \mathrm{~m}$ instead of $300 \mathrm{~m})$. The PMWE is a layer, about $2 \mathrm{~km}$ thick, rising and falling in height with a wavelike motion with a period of about $1 \mathrm{~h}$. The second panel of Fig. 1 shows the strength of radar echoes detected by the ESRAD radar with the program fca_4500. ESRAD has much less transmitter power than the EISCAT VHF radar and sees detectable scatter only when the scatter is unusually strong i.e. it sees only the PMWE, not the background ion-line scatter. Figure 1 shows that PMWE is visible to ESRAD at the same times as mentioned above for EISCAT. ESRAD also clearly sees PMWE at about 70-km height between 10:00 and 15:00 UT. This PMWE layer may be present also in the EISCAT measurements, but there it is not distinct against the background electron density. ESRAD data for the 19:0024:00 UT time interval are further examined in more detail here since the high signal levels at that time allow us to apply interferometric analysis. The results are shown in Figs. 8-13.

The first stage in further analysis is to apply the "full correlation analysis" technique, as developed and described by Briggs (1985). The principle behind this technique is that scatterers in the atmosphere lead to a diffraction pattern on the ground which moves across the antenna array, as the scatterers drift horizontally. A complicating factor is that the scatterers also change in time at a rate which may be

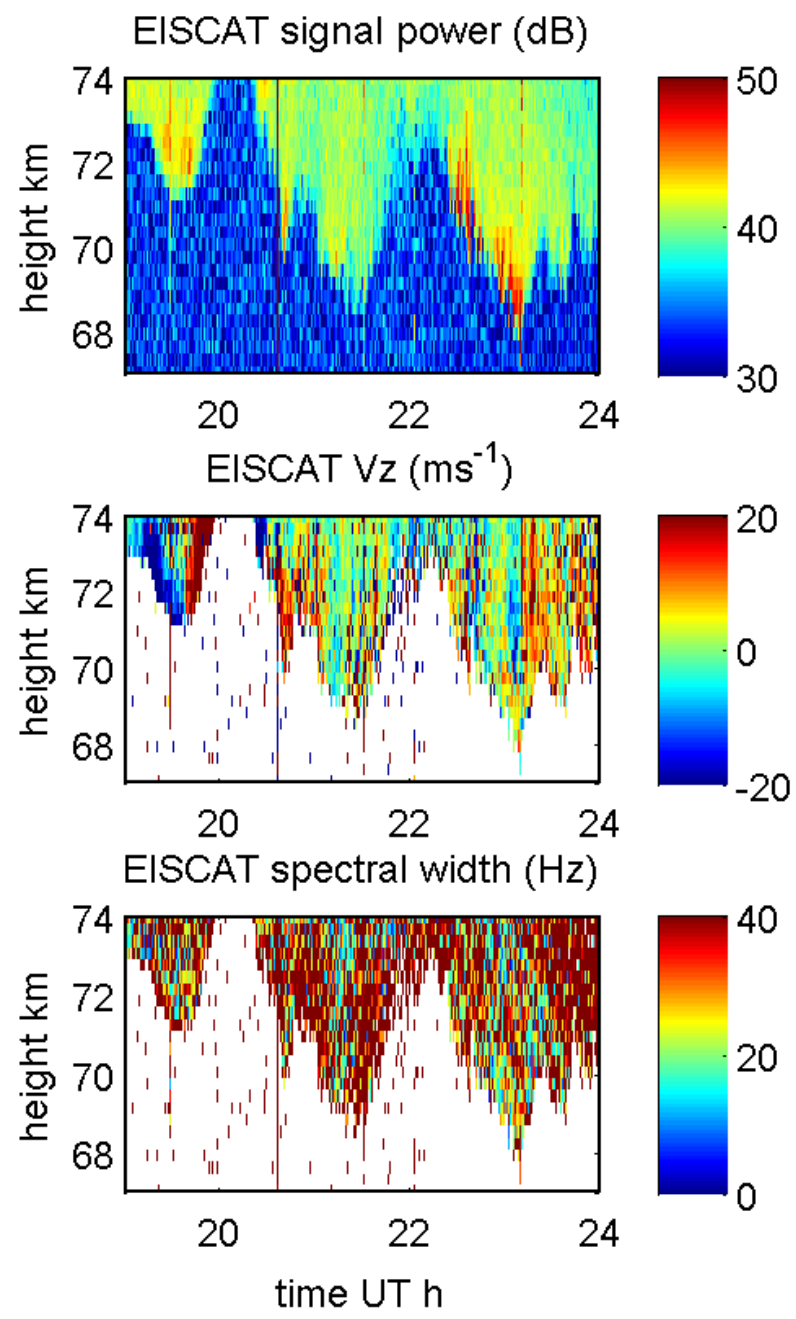

Fig. 5. EISCAT observations covering the strong PMWE event in the evening sector. Upper panel shows radar echo strength, middle panel shows echo Doppler shift (positive towards the radar), lower panel shows echo spectral width (all $30 \mathrm{~s}$ integrated data).

comparable with the drift time across the array. Under the assumption that the spatial and temporal correlation functions have the same shape, it is possible to separate temporal fading and true motion. The technique used to do this is "full correlation analysis". In principle, this can be done so long as 3 non-colinear antenna arrays are available. For ESRAD, during November 2004, 5 separate antenna arrays were available leading to an over-determined problem. Least-square fitting to all 5 available channels was used for the analysis results shown here. Scatterer fading time and scatterer drift speeds from the full correlation analysis of the data with 300$\mathrm{m}$ height resolution are shown in Fig. 8. Scatterer lifetimes are clearly short, less than $0.1 \mathrm{~s}$, but the most striking result of the analysis is the extremely high horizontal scatterer drift speeds, reaching in excess of $300 \mathrm{~m} / \mathrm{s}$, particularly at the lower edge of the PMWE between 19:00-21:00 UT, where 

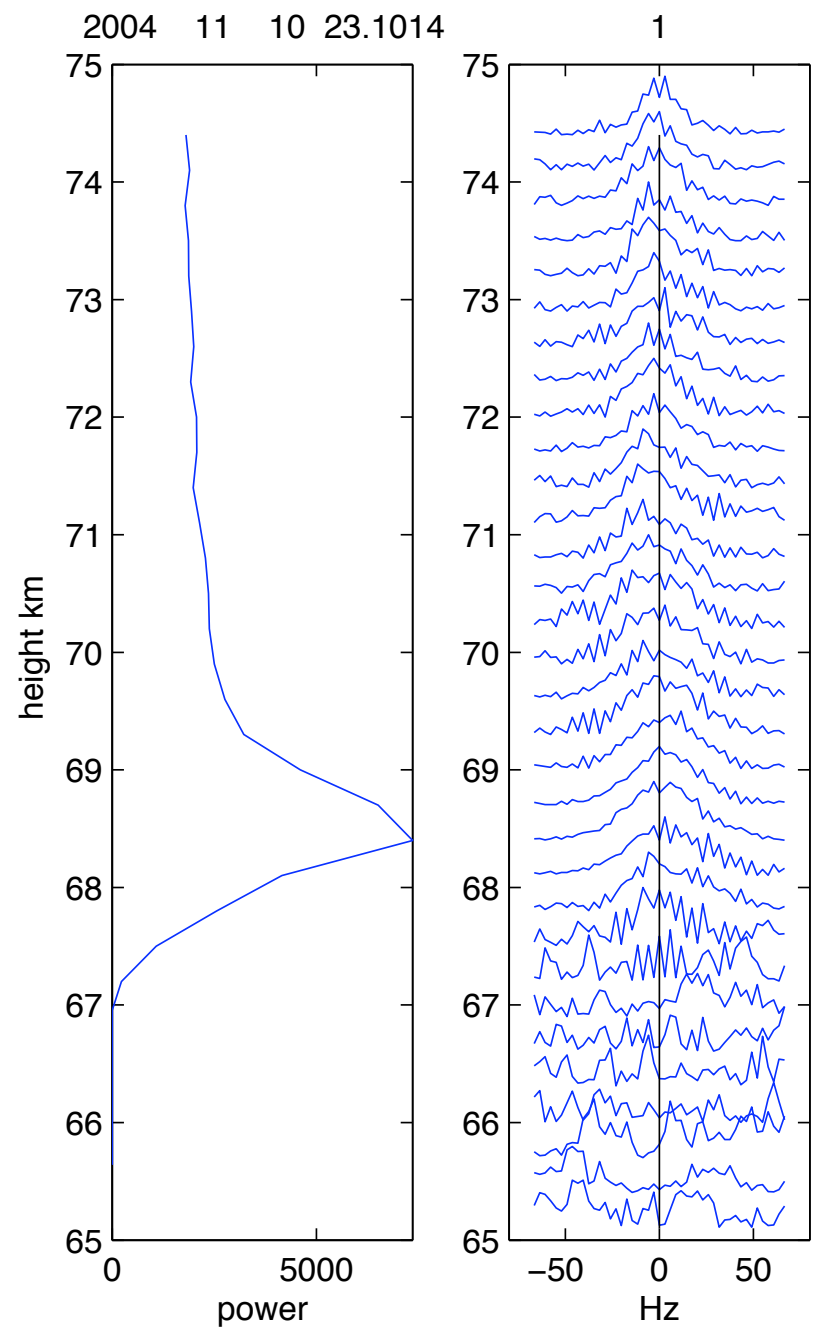

Fig. 6. EISCAT observations averaged 23:06-23:12 UT on 10 November 2004. Left-hand panel shows the height profile of echo power, right-hand panel shows echo spectra, normalised by the echo power.

the signal power is also at its highest. Figures 9 shows parameter profiles averaged between 19:36-19:42 UT which illustrate this more quantitatively, with zonal drift speed reaching $500 \mathrm{~m} / \mathrm{s}$ on the lower edge of the PMWE.

It is important to consider the reliability of the full correlation analysis as applied to these observations. Individual auto- and cross-correlations are not shown here but they have been checked to make sure that they are single valued and have a form consistent with the requirements of the technique - they are in practice found to be very close to gaussian in shape. They must also be adequately sampled so that, for further analysis, we have excluded all cases where the scatterer lifetime seemed to be less than $40 \mathrm{~ms}$, i.e. twice the available raw-data sampling interval. To estimate statistical uncertainties for the final parameters, we have compared the results of applying full correlation analysis separately to the
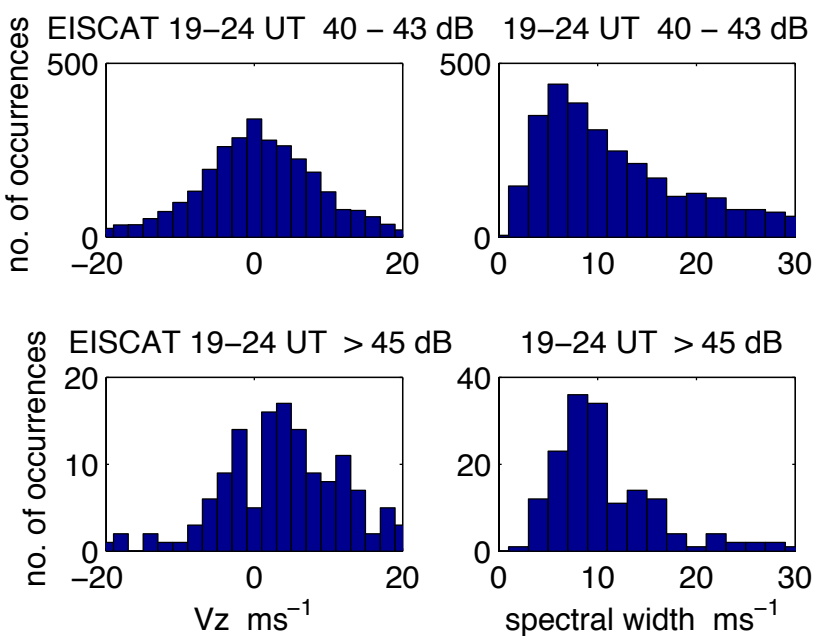

Fig. 7. Histograms showing the distribution of Doppler shifts and spectral widths for the EISCAT observations included in Fig. 5. The power interval $40-43 \mathrm{~dB}$ is chosen to represent echoes from the background ionospheric plasma, while power $>45 \mathrm{~dB}$ is representative of PMWE.

two radar modes listed in Table 2. For each mode, six-minute averages were used, for the whole PMWE event from 18:0023:00 UT. Since observations switch between the two radar modes every $22 / 25 \mathrm{~s}$, the averages should give the same results. As might be expected, the root-mean-square (rms) differences between pairs of estimates are found to vary inverseexponentially with signal-to-noise ratio (SNR), from the highest SNR values observed (ca. 10) down to about 0.1 (For SNR $<0.1$ the statistical uncertainties become very large and the results are not used further in this work). For example, for the wind components, the rms differences between the results from the two radar modes are for $\mathrm{SNR}=10, \sim 25 \mathrm{~ms}^{-1}$, for $\mathrm{SNR}=1, \sim 50 \mathrm{~ms}^{-1}$, for $\mathrm{SNR}=0.1, \sim 150 \mathrm{~ms}^{-1}$. We use the rms-difference/SNR relationship as a measure of rms uncertainties and these are shown as "error bars" in Fig. 9. It is clear that they are much less that the estimated drift speeds in the lower part of the layer, thanks to the high SNR values.

Figure 10 compares scatterer drift speeds from ESRAD with winds measured by the MF radar, averaged for the whole 1-h period 19:00-20:00 UT. The ESRAD drifts, as in Fig. 9, are far in excess of wind speeds at the bottom of the PMWE layer but the drift speeds in the upper part of the PMWE are close to the wind speeds found by the MF radar. The wind profiles measured by the MF radar are rather uniform with height. There is no indication of particularly high wind speeds nor of any windshear. As discussed for the daytime PMWE in Sect. 2, this may be due to the relatively poor height resolution of the MF wind observations. Structure in the wind profile on vertical scales of less than a few kilometres would not be resolved. 

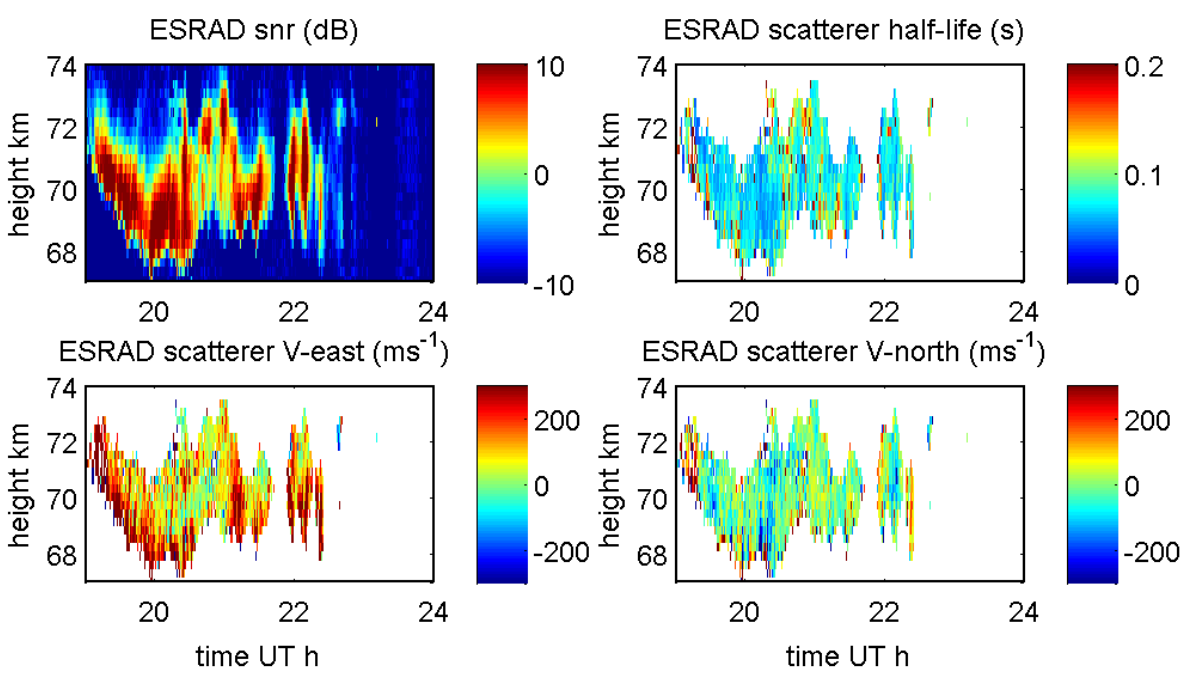

Fig. 8. Results of full correlation analysis of ESRAD data during the evening PMWE event. Top left panel shows signal-to-noise ratio, top right panel shows scatterer lifetime (time to decay to half power), bottom left panel shows eastward horizontal scatterer drift speed, bottom right panel shows northward horizontal scatterer drift speed (all 300-m height resolution, $22 \mathrm{~s}$ average data, one profile each $64 \mathrm{~s}$ ).
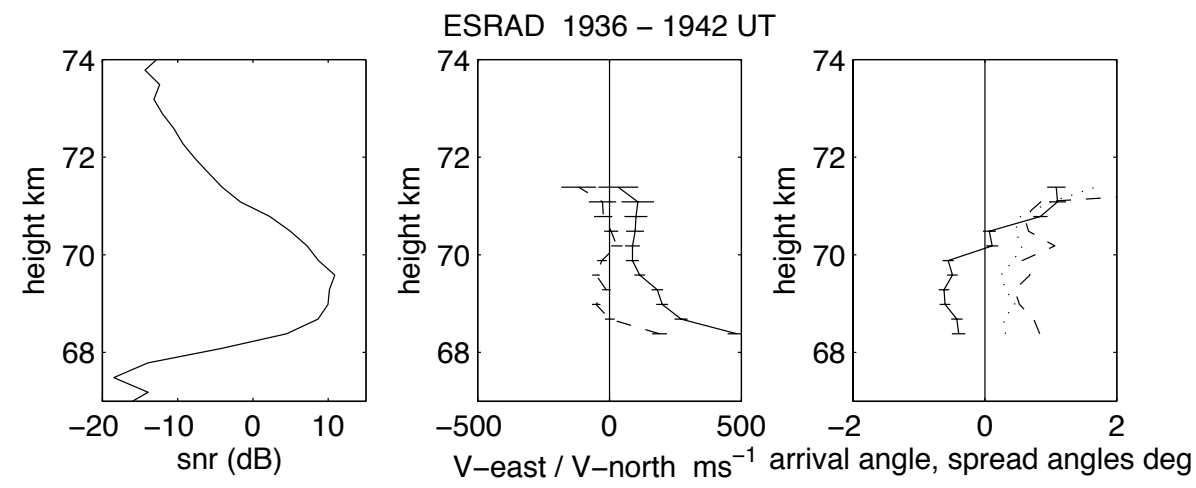

Fig. 9. Profiles of the results of ESRAD analysis averaged between 19:36-1942 UT. In this figure, the analysis has been performed for the 6 separate 20 -s time intervals when data were collected in the alias_300 mode. The results have then been averaged. First panel shows signal-to-noise ratio. Second panel shows eastward (solid line) and northward (dashed line) scatterer travel speeds. Third panel shows mean arrival angle (solid line) and angular spread in maximum (dashed line) and minimum (dotted line) directions. Error bars are statistical uncertainties estimated as described in Sect. 2.3. For clarity, error bars are not plotted for the two curves showing angular spread - for these the incertainties are ca. $\pm 0.5^{\circ}$.

An alternative way to analyse the data is in the frequency domain (e.g. Farley et al., 1981). Mathematically, it can be shown that an analysis in the frequency domain gives the same information as the full correlation analysis (Briggs, 1992). However, here we will use this method to illustrate certain aspects of the scatterer behaviour, which are conceptually clearer in this domain. In this case we compute cross-spectra between East-West and North-South antenna pairs. The cross-spectral phase can be used to locate the echoes in space (in terms of arrival angle) as a function of frequency shift (Doppler). Typical results for PMWE are shown in Fig. 11. These arrival angle maps, with colour coding showing the Doppler at each arrival angle, show the typical characteristics of PMWE illustrated in this way-echoes are confined to a short "streak", with less angular spread in one direction than in the other, with a strong, systematic change in Doppler shift from one end of the streak to the other. The length and breadth of these streaks (maximum and minimum angular spread), the mean arrival angle of the streak (angular distance from zenith) and the mean Doppler for the whole evening event are shown in Fig. 12. Height profiles of the angular spread and mean arrival angle are included in Fig. 9. It is clear in that figure that the angular spread is low in all except the uppermost part of the PMWE, including in the lowermost part where scatterer drift speeds are highest. 


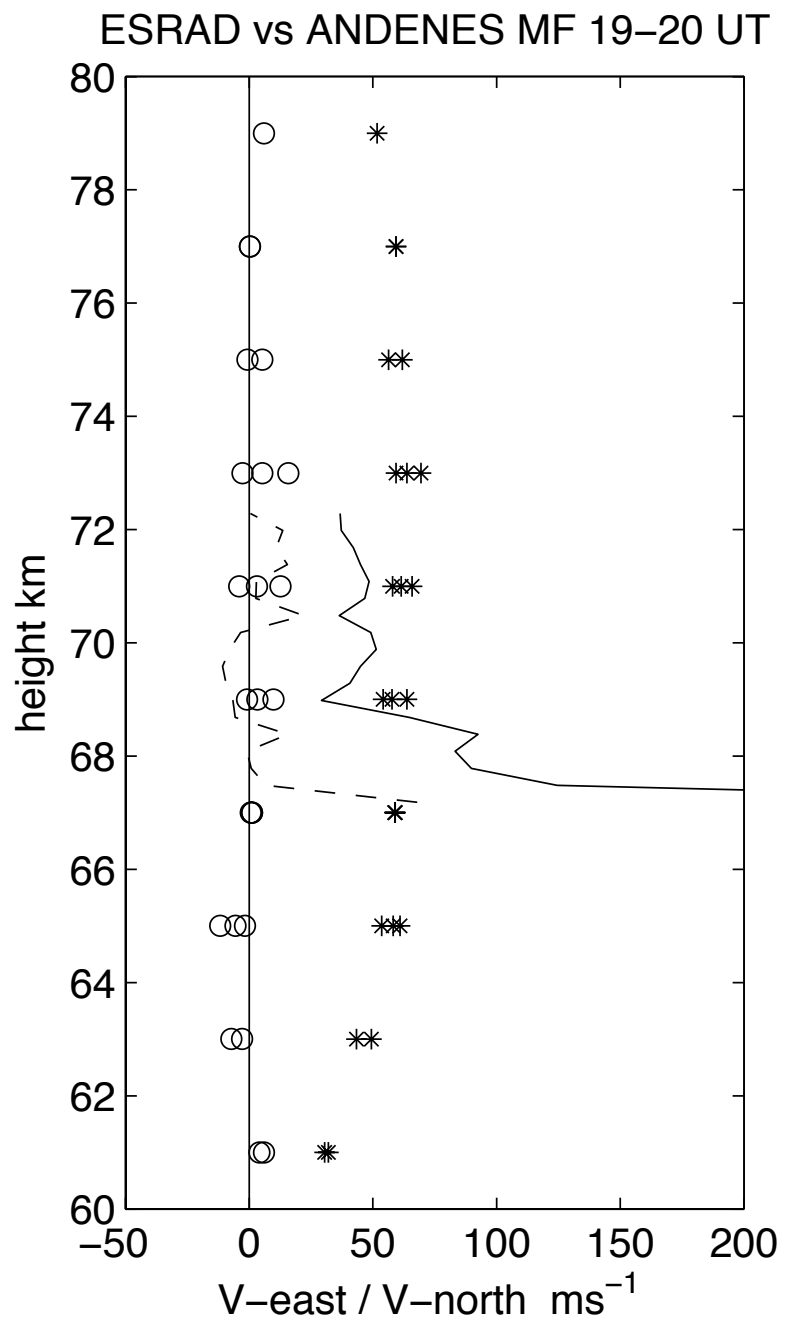

Fig. 10. Profiles of the results of ESRAD scatterer drift-speed analysis averaged between 19:00-20:00 UT (solid line is eastward drift, dashed line is northward drift), compared with winds from the Andenes MF radar for the same time interval (* show eastward wind, o show northward wind). Both 30-min and 60-min average profiles are plotted for the MF radar.

Overall, Fig. 12 shows that the "streak" like characteristics of the echoes, as illustrated in Fig. 11 apply to the whole PMWE layer. The length of the streaks (maximum angular spread) is mostly in the range $0.5-1^{\circ}$ which is systematically higher than the spread in the perpendicular direction (minimum angular spread), the latter being predominantly less than $0.5^{\circ}$. The arrival angles are for the most part within $0.5^{\circ}$ from zenith, except at the edges of the PMWE layer where they reach $1-1.5^{\circ}$. The vertical velocity varies between -10 and $+10 \mathrm{~m} / \mathrm{s}$. There is no obvious correlation between fluctuations in vertical velocity and fluctuations in arrival angle suggesting that the vertical velocity may be simply related to true vertical motion of the air due to small-scale gravity waves.
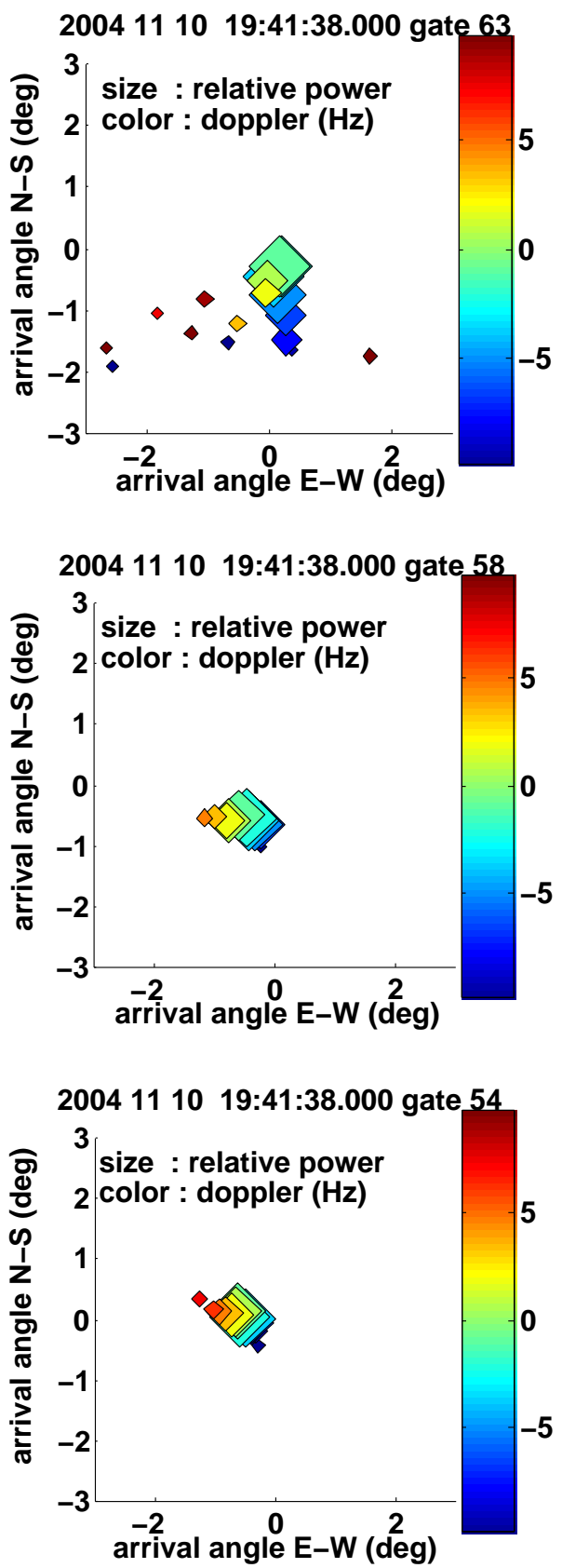

Fig. 11. Examples of arrival angle maps for ESRAD observations at the top (a), maximum (b) and base (c) of the PMWE layer. Examples are from averaged cross-spectra between 19:36-19:42 UT. Each coloured square is plotted at the angular position from which the echo arrives (from the phase of the cross-spectra between EastWest and North-South antenna-segment pairs, respectively). The colour shading indicates the Doppler shift corresponding to the particular frequency bin and the area of the square is proportional to the cross-spectral power from the North-South antenna-segment pairs. Points are plotted for all frequencies where the spectral power is at least half of the maximum. 

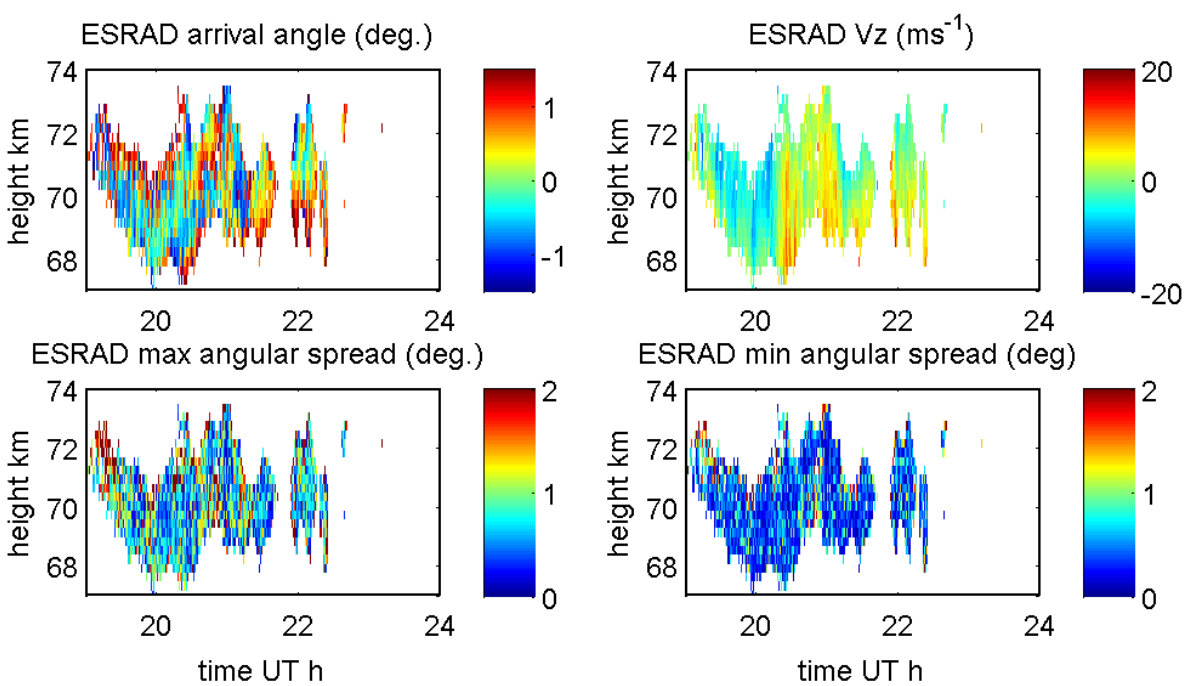

Fig. 12. Results of frequency-domain spatial interferometric analysis of ESRAD data during the evening PMWE event. Top left panel shows mean signal arrival angle (degrees from zenith, positive in the NE or SE sectors, negative in the NW or SW sectors), top right panel shows mean scatterer Doppler, bottom left panel shows angular spread of echoes along the direction where the spread is greatest, bottom right panel shows angular spread of echoes along the direction where the spread is least. Angular spread is the full angular width of the region where echo strength exceeds half of the of the maximum in the cross-spectral amplitude. (All 300-m height resolution, 22-s average data, one profile each $64 \mathrm{~s})$.

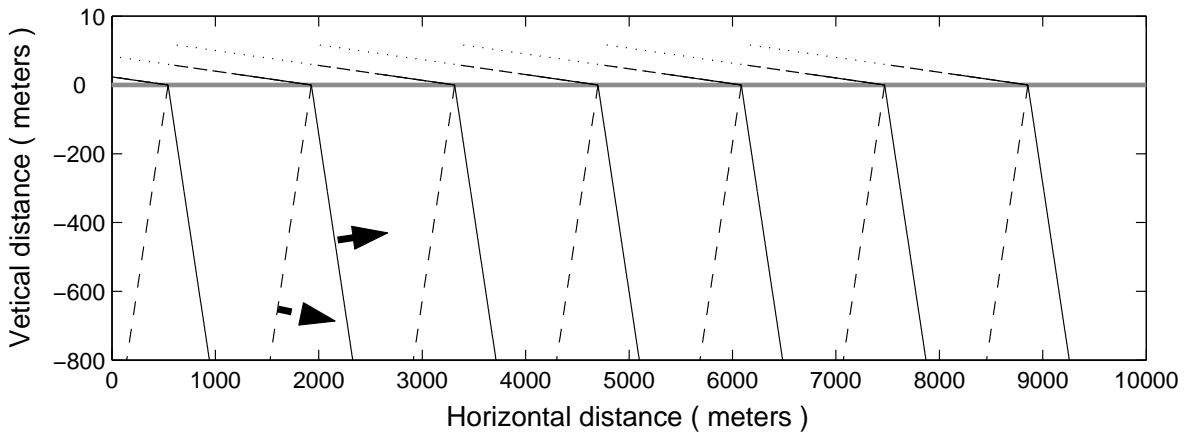

Fig. 13. Sketch illustrating the geometry of the generation of evanescent viscosity waves (above the gray line) by partially reflected acoustic waves (below the gray line). Solid and dashed lines in the lower part indicate wave fronts of the incident and reflected waves, respectively. In the upper part, wave fronts of the evanescent waves are indicated as solid lines, changing to dashed and then to dotted lines at increasing distances above the reflecting level, to indicate the rapid attenuation of the wave amplitudes in these evanescent waves. The scales are appropriate for an incident infrasonic wave of 5-s period producing evanescent waves with a wavelength of $3 \mathrm{~m}$. Note that the vertical scale is not the same above and below the reflecting level (gray line).

\section{Discussion}

\subsection{Turbulence}

As mentioned in the introduction, previous studies of PMWE have indicated that they are too strong to be explained as direct effects of reasonable levels of isotropic neutral turbulence (Stebel et al., 2004; Belova et al., 2005; Kirkwood et al., 2005). Simultaneous observations of temperature and wind profiles (by sounding rockets) have further shown that PMWE occur in regions where turbulence cannot be expected (Richardson number $>1$ ) (Kirkwood et al., 2003, 2005). A possibility remains that PMWE might be due to highly anisotropic "fossil" structure produced above and below a turbulent zone, for example a turbulent wind-shear zone (e.g. Werne and Fritts, 1999). There are aspects of the present observations which provide strong arguments against this. The foremost argument is the extremely high scatterer drift speeds. "Fossil" turbulent structures would be embedded in the neutral gas and travel with the wind. The observed scatterer drift speeds are far in excess of any reasonable wind speed. The high speeds indicate the effects of a propagating 

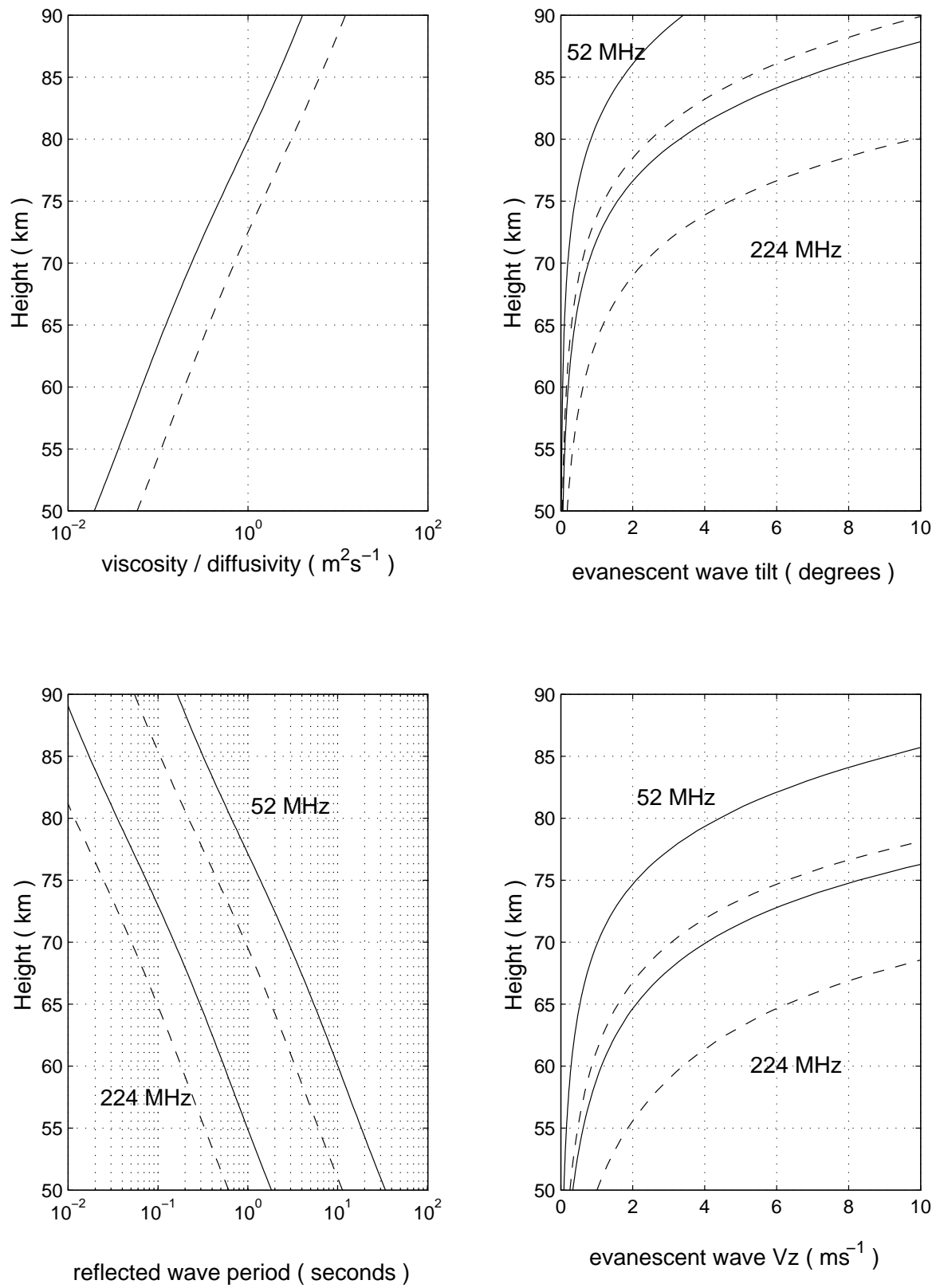

Fig. 14. Upper-left panel: solid line shows kinematic viscosity for midwinter, $60 \mathrm{deg} \mathrm{N}$ latitude, calculated from the MSIS90E neutral atmosphere model (Hedin, 1991). This line also indicates electron diffusivity in the case when only positive molecular ions are present. The dashed line indicates a factor 3 increase in electron diffusivity such as would be produced if the ratio of negative-ions to electrons $(\Lambda)$ is 2 (Hill, 1978). Solid and dashed lines in the other panels show calculated values based on these two diffusivity profiles. Lower left panel: calculated acoustic wave periods which will produce evanescent waves matching the radar Bragg scale for radars at $224 \mathrm{MHz}$ and $52 \mathrm{MHz}$. Upper-right panel: calculated tilt of the evanescent-wave wave-fronts, relative to the reflecting surface. Lower-right panel: calculated drift speed of the evanescent-wave wave-fronts, away from the reflecting surface.

wave rather than structures carried by a neutral wind. This is further supported by the systematic change in Doppler across the angular region from which echoes are obtained (Fig. 11).

A second argument against a role for turbulence is the very strong aspect sensitivity with angular spread of the echoing region generally as small as $0.3^{\circ}$ in one direction. Hocking et al. (1990) have developed a quantitative relation between observed angular spread $\left(\Theta_{\mathrm{s}}\right)$ and the 1/e horizontal length scale $(\mathrm{L})$ of the scattering structures for a radar wavelength $\lambda$ (for small values of $\Theta_{\mathrm{s}}$ ):

$\mathrm{L}=0.11 \lambda / \sin \Theta_{\mathrm{s}}$. 
The definition of $\Theta_{\mathrm{s}}$ is slightly different from the angular spread $(\Theta)$ in the present study. $\Theta_{\mathrm{S}}$ is the $1 / \mathrm{e}$ half width of the angular distribution of echo power, whereas $\Theta$ is the $1 / 2$ full width of the angular distribution of echo amplitude, leading to a slightly revised relation in the present case:

$\mathrm{L}=0.13 \lambda / \sin (\Theta / 2)$.

Using this relation, we find that the typical $0.3^{\circ}$ angular spread observed by ESRAD in the PMWE would require horizontal length-scales of the scattering structures of about $300 \mathrm{~m}$, about 100 times the vertical scale to which the radar is sensitive. This is larger than seems reasonable for anisotropic turbulent structures and rather suggests quasi-specular echoes from some other kind of a horizontally-extended structure.

Hocking and Hamza (1997), have considered in some detail the maximum horizontal-to-vertical scale ratio which could be result from anisotropic atmospheric turbulence. They found that for a $50-\mathrm{MHz}$ radar, a $40 \mathrm{~ms}^{-1} \mathrm{~km}^{-1}$ windshear and turbulent energy dissipation rate $0.01 \mathrm{Wkg}^{-1}$, this ratio should not exceed about 1.2. Hocking and Hamza (1997) show that increasing the turbulent energy reduces this ratio (in proportion to the inverse cubic root of the energy), whereas the ratio will increase in proportion to the wind shear. In practice, lower energy dissipation rates would not be expected to give detectable radar echoes and there is no room to propose even a wind shear of $40 \mathrm{~ms}^{-1} \mathrm{~km}^{-1}$ for the PMWE in this case. As Figs. 9 and 12 show, the layer of highly-aspect sensitive echoes extends over at least $2 \mathrm{~km}$ in height while the winds on this height scale are essentially constant (Fig. 10). So the considerations of Hocking and Hamza support our conclusion that the PMWE in this case are some kind of specular echoes.

The third argument against turbulence is the remarkable similarity in EISCAT spectral widths between PMWE and background incoherent scatter, in both the pre-noon and evening examples, despite the fact that the spectral widths differ by about a factor 3 between the two examples. If the EISCAT PMWE were caused by turbulence, the spectral width of the scattered spectra would be determined by the turbulent velocity fluctuations in the direction of observation (vertical in this case), and enhanced echo layers observed by the EISCAT VHF radar in the winter mesosphere have previously been interpreted in this way (Collis et al., 1992). As discussed in the latter paper, the spectral width is proportional to the square root of both the energy dissipation rate and the buoyancy frequency. For typical buoyancy frequencies of 1.7-2.3 rad/s (Kirkwood et al., 2005), the observed EISCAT spectral widths of $\sim 7 \mathrm{~Hz}$ in Fig. 3, and $\sim 20 \mathrm{~Hz}$ in Fig. 6, would correspond to energy dissipation rates of $75-100 \mathrm{~mW} / \mathrm{kg}$ and $600-800 \mathrm{~mW} / \mathrm{kg}$, respectively, if interpreted as due to turbulence. So, the turbulence would have to be much stronger in the evening than in the morning, and considerably higher than the values considered typical for the relevant heights during winter, especially for the evening
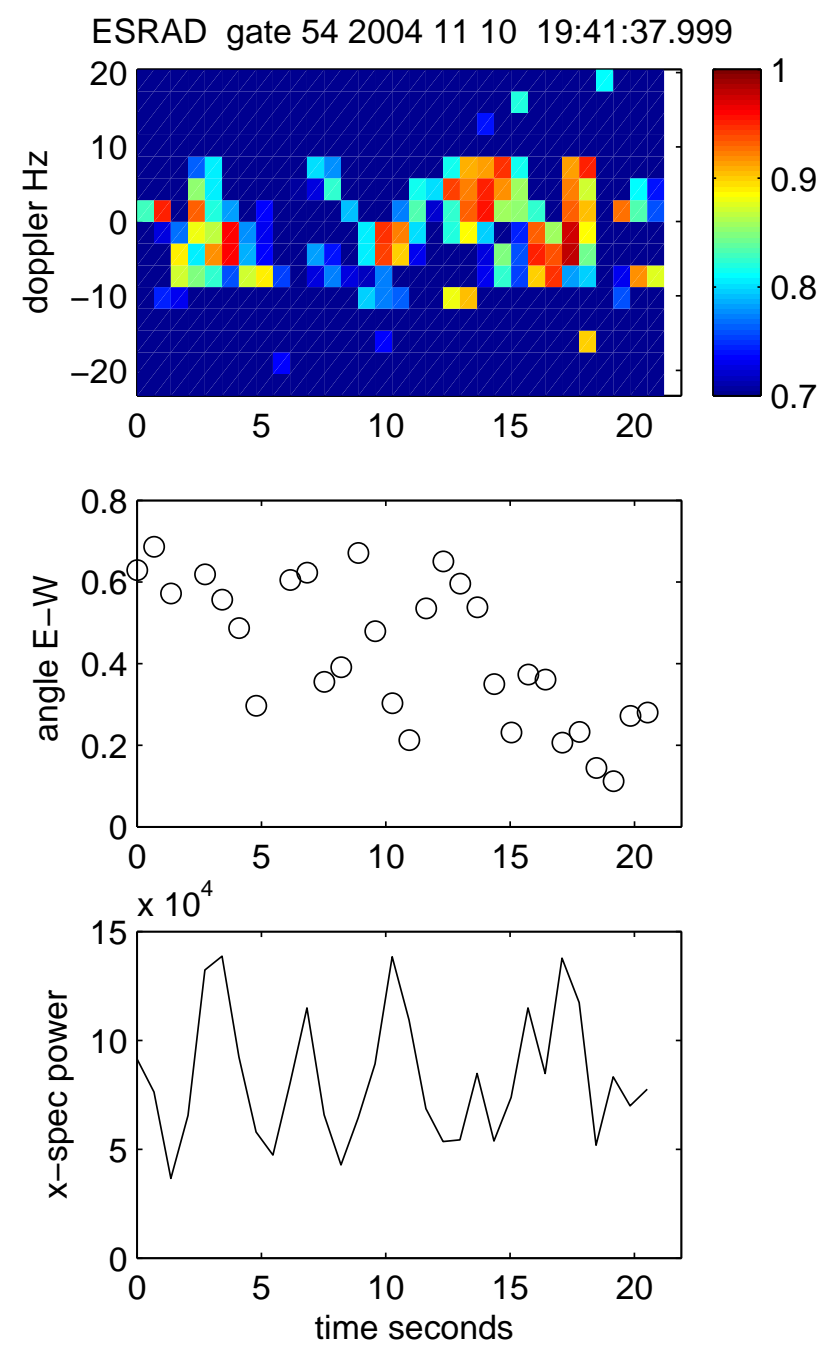

Fig. 15. ESRAD observations for the 20-s interval 19:41:1519:41:38 at the base of the PMWE layer. Upper panel shows cross spectral coherence for the signals from an East-West antennasegment pair. Middle panel shows the east-west angle of arrival for the signal at maximum coherence (coherence $>0.9$ ). Third panel shows the spectral power at zero Doppler.

case (Luebken et al., 1993). This would be surprising, but is of course not impossible. However the close similarity in spectral widths inside and outside the PMWE gives cause to doubt that the spectral widths are determined by turbulence, since spectral width outside the PMWE should be determined by completely different processes.

Above and below the PMWE, EISCAT is expected to measure "ion-line" scatter from the background plasma. In the Dregion ion-line, the rate of viscous damping of ion-acoustic waves is considered to be responsible for the spectral width and this depends on both the ion composition and the neutral density (e.g. Mathews, 1984). The height difference between the spectra just above the PMWE peaks in Figs. 3 and 6 is about $2.5 \mathrm{~km}$, so the neutral density will be slightly lower 
in the evening case - this can explain about a factor 1.4 increase in spectral width. The spectral widths vary by about a factor 3, leaving about a factor 2 to be explained by changed ion composition. A ratio of negative ions to electrons of 3 for the evening layer and 1 for the pre-noon layer would result in this factor (Mathews, 1984), and is not unreasonable from considerations of ion-chemistry (Kirkwood et al., 2002a). If turbulence were responsible for PMWE, it could in principle be merely coincidence that the air-parcel velocities have just the speeds needed to produce the same spectral width as ion-acoustic wave damping, in the two cases. However, the chance of such a happy coincidence occurring in both examples would seem to be rather small. Fortunately, there is an alternative explanation available.

\subsection{Infrasound and viscosity waves}

Hocking et al. (1991) and Hocking (2003) have proposed that highly damped viscosity waves, resulting from partial reflection of infrasound or gravity waves could result in highly aspect sensitive scattering layers in the stratosphere and mesosphere. The principle is illustrated in Fig. 13. A gravity/infrasound wave approaches a boundary from below (phase fronts in solid lines) and is partially reflected (dashed lines) at some horizontal boundary (grey line), which might be a sharp increase in temperature or a wind shear. An evanescent disturbance, a viscosity wave, is generated at the boundary (short lines above the boundary). The phasefronts of the viscosity waves are very close to parallel with the reflecting surface and the "wavelength" is determined by the kinematic viscosity and the period of the incident gravity/infrasound wave. The viscosity wave is highly damped, largely disappearing after a half wavelength (indicated by the dashed and dotted transitions in the phase fronts in Fig. 13). To produce radar scatter, the wavelength of the viscosity wave $\left(\lambda_{z}\right)$ has to match the radar Bragg length, which is half the radar wavelength. So, for a particular probing radar and a particular kinematic viscosity (v), all incident waves of one particular period $(\mathrm{T})$ can lead to effective scattering structures. According to Hocking (2003):

$\lambda_{\mathrm{z}}=2(\pi \nu \mathrm{T})^{0.5}$

Radar scatter at mesospheric heights is in practice caused by fluctuations in electron density, not directly by the fluctuations in neutral density which are the immediate result of the viscosity waves. However, fluctuations in neutral density are rapidly transmitted to the ion gas by collisions, and further to the electron gas by the ambipolar electric field. In the D-region plasma, the viscosity waves generate diffusion waves (Hocking, 2003) which are also known as highly damped ion-acoustic waves (Mathews, 1984). When only positive molecular ions are present, these plasma waves have the same wavelength and decay characteristics as the viscosity waves (this is the case of Schmidt number $(S)=1$, see e.g. Hill, 1978). When negative ions are present, the electron diffusivity is increased and shorter period diffusion waves are needed to match the radar Bragg scale (the case of $S \ll 1$ ). If charged particles of higher mass, such as dust, are present, the electron diffusivity can be decreased so that longer period diffusion waves (dust-acoustic waves) can match the radar Bragg scale (the case of $S \gg 1$ ). However, there is no strong evidence as yet for substantial quantities of charged dust at the heights of our PMWE observations in the winter mesosphere. (Stebel et al., 2004, used joint radar/lidar observations to try to determine whether an aerosol-particle layer could be associated with PMWE but the results were inconclusive.) The modified form of Eq. (2a), appropriate for diffusion (or highly damped ion-acoustic) waves with vertical wavelength $\lambda_{D}$, becomes:

$\lambda_{\mathrm{D}}=2(\pi \mathrm{S} v \mathrm{~T})^{0.5}$

The appropriate incident-wave periods (T) which can cause radar returns for the EISCAT VHF and ESRAD radars in the mesosphere are shown in Fig. 14, based on kinematic viscosity calculated using the MSIS90E model for midwinter (Hedin 1991). Figure 14 also shows calculations of the tilt and vertical travel speed of the wave-fronts of the evanescent waves (relative to the reflecting surface).

Figure 14 shows that infrasonic waves with periods ca $1-10 \mathrm{~s}$ could be effective in generating scattering structures for the ESRAD radar $(52 \mathrm{~Hz})$ at PMWE heights of $\sim 60$ $70 \mathrm{~km}$. Periods $\sim 10$ times less are needed for the EISCAT VHF radar $(224 \mathrm{MHz})$. Infrasonic waves, caused by many sources as widely varying as ocean swell, thunderstorms, supersonic aircraft and industrial plants, are known to travel long distances through the atmosphere (e.g. Blanc, 1985). They can be partially or fully reflected by temperature gradients or by wind shears, which can easily provide largely horizontal reflecting surfaces in the atmosphere. Observations of infrasound are made by several interferometric arrays of microbarographs in many parts of the world, and many studies have been published in the literature regarding long-distance propagation through the upper atmosphere, including the mesosphere (see, e.g. Drob et al., 2003). It is notable that a peak in the infrasound spectrum for periods of a few seconds is often observed and the source has been established as ocean swell (see, e.g. Garcés et al., 2004). This is exactly the period-range needed to cause diffusion waves matching the Bragg scale for the ESRAD radar in the conditions of the present PMWE observations.

Hocking (2003) further made quantitative estimates of the potential for infrasonic waves to cause VHF radar echoes from the mesosphere and concluded that detectable echoes could reasonably be produced. A further aspect of this mechanism, which Hocking (2003) does not consider, but which seems clear from consideration of Fig. 13, is that the region of enhanced scatter should move horizontally at the horizontal trace speed of the incident infrasonic wave, which will be equal to or somewhat higher than the speed of sound, which is about $300 \mathrm{~m} / \mathrm{s}$. If the incident infrasonic waves have an 
isotropic distribution travel direction, and if the partial reflection is caused by a temperature gradient, the average drift of many scattering regions should be close to that of the neutral wind. This can explain the ESRAD scatterer drift characteristics in the upper part of the PMWE layer. However, if there is anisotropy in the travel directions of the infrasonic waves present, or if the reflecting surface is due to a wind shear so that the reflection is anisotropic, one would expect a systematic drift of the scatterers in some direction. Infrasonic waves with wavelengths $\sim 0.3$ to $\sim 3 \mathrm{~km}$ (periods $1-10 \mathrm{~s}$ ) can be responsible for diffusion waves matching the ESRAD Bragg scale. The ESRAD radar beam covers a region which is about $6 \mathrm{~km}$ in diameter at PMWE heights. This means that ESRAD might see single scattering regions moving through the beam at $300 \mathrm{~m} / \mathrm{s}$ or more, particularly in the case of aspect sensitive scatterers which would be seen only close to zenith and not throughout the 6-km wide beam. If only a single scattering region is present, then all radar returns will be from the same region, they will be in phase and a very strong echo will be returned. This fits remarkably well with the observed characteristics of the lower half of the ESRAD PMWE layer in Fig. 8. In fact, occasional short periods can be found in the ESRAD data which fit this description almost exactly. Figure 15 shows such an interval, where successive wave fronts at about 3-s interval can be discerned moving across the field of view.

The period-range of the infrasonic waves which can be responsible for diffusion waves matching the Bragg scale for EISCAT is $0.1-1 \mathrm{~s}$, corresponding to wavelengths for the infrasound of only $\sim 30-300 \mathrm{~m}$. The EISCAT radar beam covers a region which is about $3 \mathrm{~km}$ in E-W diameter at PMWE heights. This means that EISCAT is unlikely to see single scattering regions moving through the beam. On the other hand, the viscosity waves or ion-acoustic waves which match the EISCAT Bragg length in this case will have significant vertical drift speeds of $1-5 \mathrm{~m} / \mathrm{s}$ (Fig. 14, lower right panel). This can very elegantly explain the Doppler shifts of the EISCAT PMWE spectra in Fig. 3 and is remarkably close to the observed slight statistical differences in vertical drift speeds between EISCAT PMWE and EISCAT background ion-line observations (Figs. 4 and 7). The most common vertical drift speeds inside the PMWE in Fig. 4 are in the interval -2 to $3 \mathrm{~m} / \mathrm{s}$, corresponding to upward moving scatterers. In Fig. 7, there are two peaks in the histogram - at vertical drift speeds -2 to $-3 \mathrm{~m} / \mathrm{s}$ and at +3 to $+5 \mathrm{~m} / \mathrm{s}$. This can be explained if there are channels for acoustic waves present, in which infrasonic waves are reflected downward at the upper boundary but upward at the lower boundary. The result in the case of EISCAT would be both upward and downward diffusing viscosity waves, respectively. Note that temperature minima associated with the strong gravity waves which are common in the winter, high-latitude mesosphere (e.g. Lübken and von Zahn, 1991), could provide such channels. They will be effective only for infrasound with wavelengths much shorter than vertical wavelength of the gravity waves. Since wavelengths of a few kilometres are common for the gravity waves, the channels should be more effective for the $30 \mathrm{~m}-$ $300 \mathrm{~m}$ infrasound waves we expect to be involved in the EISCAT PMWE, than for the $300 \mathrm{~m}-3 \mathrm{~km}$ waves we propose to be responsible for the ESRAD PMWE.

The close similarity in spectral widths between PMWE and EISCAT background incoherent scatter (at the same height) becomes a natural consequence of the fact that both are due to the damping rate of ion-acoustic waves, which is determined by the neutral density and ion composition. The slight increase in spectral width of EISCAT PMWE echoes in Figs. 4 and 7, compared to the background ion-line, can be explained as the contribution of off-perpendicular returns with high transverse velocities - an off perpendicular angle of $1^{\circ}$ with transverse speed in excess of $300 \mathrm{~m} / \mathrm{s}$ gives $5 \mathrm{~m} / \mathrm{s}$ or more in spectral broadening.

Previously published characteristics of PMWE also find natural explanations in the framework of this theory. The close correlation between descending PMWE and the descending phase of an inertio-gravity wave (Belova et al., 2005) can be explained if the wind-shear or temperature perturbation caused by the inertio-gravity wave causes partial reflection of infrasonic waves. Kirkwood at al. (2002a) showed that PMWE at $52 \mathrm{MHz}$ disappear when negative ion concentrations exceed about 100 times the number of free electrons (i.e. for $\Lambda>\sim 100$ ), while Belova et al. (2005) found that PMWE at $224 \mathrm{MHz}$ seemed to be detectable only at slightly lower $\Lambda$. This can be explained by the rapid increase in electron diffusion rate approximately proportionally to the ratio negative ions to electrons (Hill , 1978). For $\Lambda=100$, infrasonic wave periods which are 100 times less would be needed to produce diffusion waves in the electron gas which match the Bragg criteria for any particular radar, compared to the situation when no negative ions are present (Eq. 2b). Infrasonic waves with periods less than $\sim 0.05 \mathrm{~s}$ (frequency $>\sim 20 \mathrm{~Hz}$ ) are heavily attenuated in the atmosphere so they are unlikely to be available in the mesosphere to generate the PMWE (Blanc, 1985). This is indeed about 100 times less than the infrasound periods of about 2-10s needed to explain the daytime PMWE detected at $52 \mathrm{MHz}$ in this study. Since the infrasound periods needed to match the Bragg scale at $224 \mathrm{MHz}$ are only $0.2-1 \mathrm{~s}$, even in the daytime when low concentrations of negative ions are expected, the PMWE at $224 \mathrm{MHz}$ can be expected to disappear for $\Lambda>\sim 10$.

One property of PMWE as seen by EISCAT, however, does not have an immediate explanation with this theory. The EISCAT PMWE observations reported by Belova et al. (2005) were made with the antenna directed at 60-deg elevation, not vertically. So it seems that EISCAT PMWE are not particularly aspect sensitive and can be readily observed far from the vertical. To explain this, we have to propose that partial reflection of $0.1-1 \mathrm{~s}$ infrasonic waves occurs also from surfaces at rather large tilts from horizontal, or that evanescent ion-acoustic waves forced in the vertical direction somehow cause an enhanced level of more isotropic 
ion-acoustic fluctuations. It should be remembered that the EISCAT system is extremely powerful and is capable of detecting extremely small fluctuations in radar refractive index. The PMWE seen by EISCAT (e.g. Figs. 3 and 6) are only about one order of magnitude above the level of the thermal fluctuations in the plasma which cause the background ionline scatter. It does not seem unreasonable to suggest that a cascade of fluctuations, from strong, horizontally stratified, large scale fluctuations (seen directly by ESRAD), to weak, more isotropic, smaller scale fluctuations (detected by EISCAT) could take place.

\section{Conclusions}

The ESRAD 52-MHz and EISCAT 224-MHz have made simultaneous observations of long-lasting Polar Mesosphere Winter Echoes during a solar proton event in November 2004. Interferometric analysis of the ESRAD observations shows that scattering structures are highly aspect sensitive and that they move horizontally at speeds in excess of the speed of sound. In some cases, individual scattering regions can be tracked, with successive scattering regions crossing the radar at periods of a few seconds. The EISCAT radar has observed the spectral width of the scattered signal both inside and outside the PMWE region. Although the total scattered power is an order of magnitude or more higher within the PMWE region, the spectral widths do not differ significantly between the PMWE and the background plasma immediately above the PMWE. This applies both in pre-noon and evening conditions where the spectral widths differ by about a factor 3.

We propose that evanescent diffusion waves generated at horizontal boundaries by partial reflection of infrasound, as proposed by Hocking et al. (1991), and refined by Hocking (2003), provide the most reasonable explanation of these observations. We note that infrasound from ocean swell with periods of a few seconds is of just the right frequency to explain the ESRAD observation. We also note that the very high horizontal travel speeds seen by ESRAD find a natural explanation in the phase-trace speed of the infrasonic waves. Finally we note that evanescent diffusion waves as described by Hocking (2003) are in essence the same as the highly-damped ion-acoustic waves which are considered by Mathews (1984) as the basis of incoherent scatter from the D-region. This provides a natural explanation for the EISCAT observations - the spectral width is determined by the damping rate of ion acoustic waves while the level of the ionacoustic fluctuations is due to random thermal fluctuations outside the PMWE but is increased by the energy transfer from infrasound within the PMWE layer.

Acknowledgements. This research has to a large extent been funded by the Swedish research Council (VR). EISCAT is an international association supported by the research councils of Finland (SA), France (CNRS), Germany (MPG), Japan (NIPR), Norway (NFR),
Sweden (VR) and the United Kingdom (PPARC). ESRAD is a joint venture between Swedish Institute of Space Physics and Swedish Space Corporation, Esrange.

Topical Editor M. Pinnock thanks M. Jarvis, W. Hocking and another referee for their help in evaluating this paper.

\section{References}

Balsley, B. B., Ecklund, W. L., and Fritts, D. C.: VHF echoes from the high-latitude mesosphere and lower thermosphere: observations and interpretations, J. Atmos. Sci., 40, 2451-2466, 1983.

Belova, E., Kirkwood, S., Ekeberg, J., Osepian, A., Häggström, I., Nilsson, H., and Rietveld, M.: Polar mesosphere winter echoes observed simultaneously by EISCAT VHF and ESRAD MST radars, Ann. Geophys., 23, 1239-1247, 2005.

Blanc, E.: Observations in the upper atmosphere of infrasonic waves from natural or artificial sources: a summary, Ann. Geophys., 3 (6), 673-688, 1985.

Briggs, B. H.: The analysis of spaced sensor records by correlation techniques, MAP Handbook, 13, 166-168, 1985.

Briggs, B. H. and Vincent, R.A.: Spaced antenna analysis in the frequency domain, Radio Sci., 27, 117-129, 1992.

Cho, J. Y. N. and Roettger, J.: An updated review of polar mesosphere summer echoes: Observation, theory and their relationship to noctilucent clouds and subvisible aerosols, J. Geophys. Res., 102, 2001-2020, 1997.

Collis, P. N., Rietveld, M. T., Roettger, J., and Hocking, W. K.: Turbulence scattering layers in the middle-mesosphere observed by the EISCAT 224-MHz radar, Radio Sci., 27, 97-107, 1992.

Drob, D. P., Picone, J. M., and Garcés, M. A.: The Global Morphology of Infrasound Propagation, J. Geophys. Res., 108, doi:10.1029/2002JD003307, 2003.

Farley, D. T., Ierkic, H. M., and Fejer, B. G.: Radar interferometry: a new technique for studying plasma turbulence in the ionosphere, J. Geophys. Res., 86, 1467-1472, 1981.

Garces, M. A., Willis, M., Hetzer, C., Le Pichon, A., and Drob, D.: On using ocean swells for continuous infrasonic measurements of winds and temperature in the lower, middle, and upper atmosphere, Geophys. Res. Lett., 31, doi:10.1029/2004GRL020696, 2004.

Hedin, A. E.: Extension of the MSIS thermosphere model into the middle and lower atmosphere, J. Geophys. Res., 96, 1159-1172, 1991.

Hill, R. J.: Nonneutral and quasi-neutral diffusion of weakly ionized multiconstituent plasma, J. Geophys. Res., 83, 989-998, 1978.

Hocking, W. K.: Evidence for viscosity, thermal conduction and diffusion waves in the Earth's atmosphere, Review of Scientific Instruments, 74(1), 420-426, 2003.

Hocking, W. K., Fukao, S., Tsuda, T., Yamamoto, M., Sato, T., and Kato, S.: Aspect sensitivity of stratospheric VHF radio wave scatterers particularly above 15-km altitude, Radio Sci., 25, 613627, 1990.

Hocking, W. K., Fukao, S., Yamamoto, M., Tsuda, T., and Kato, S.: Viscosity waves and thermal-conduction waves as a cause of specular reflectors in radar studies of the atmosphere., Radio Sci., 26, 1281-1303, 1991.

Hocking, W. K. and Hamza, A. M.: A quantitative measure of the degree of anisotropy of turbulence in terms of atmospheric pa- 
rameters, with particular relevance to radar studies, J. Sol. Terr. Atmos. Phys., 59, 1011-1020, 1997.

Hunten, D. M., Turco, R. P., and Toon, O. B.: Smoke and dust particles of meteoric origin in the mesosphere and thermosphere, J. Atmos. Sci., 37, 1342-1357, 1981.

Kelley, M. C., Farley, D. T., and Röttger, J.: The effect of cluster ions on anomalous VHF backscatter from the summer polar mesosphere, Geophys. Res. Lett., 14, 1031-1034, 1987.

Kirkwood, S., Barabash, V., Belova, E., Nilsson, H., Rao, T. N., Stebel, K., Osepian, A., and Chilson, P. B.: Polar mesosphere winter echoes during solar proton events, Advances in Polar Upper Atmosphere Research, 16, 111-125, 2002a.

Kirkwood, S., Barabash, V., Belova, E., Nilsson, H., Rao, T. N., Stebel, K., Blum, U., Fricke, K.-H., Osepian, A., and Chilson, P. B.: Polar mesosphere winter echoes by ESRAD, EISCAT and lidar, Memoirs of the British Astronomical Association, vol 45, paper 07, 2002b.

Kirkwood, S., Belova, E., Blum, U., Croskey, C., Dalin, P., Fricke, K.-H., Goldberg, R. A., Mitchell, J. D., and Schmidlin, F.: Polar mesosphere winter echoes during MaCWAVE, Ann. Geophys., accepted, 2005.

Lübken, F. J. and von Zahn, U.: Thermal structure of the mesopause region at polar latitudes, J. Geophys. Res., 96, 20 841-20857, 1991.

Lübken, F.-J., Hillert, W., Lehmacher, G., and von Zahn, U.: Experiments revealing small impact of turbulence on the energy budget of the mesosphere and lower thermosphere, J. Geophys. Res., 98, 20369-20384, 1993.
Mathews, J. D.: The incoherent scatter radar as a tool for studying the ionospheric D-region, J. Atmos. Terr. Phys., 11, 975-986, 1984.

Rapp, M. and Luebken, F.-J.: Polar mesosphere summer echoes (PMSE): Review of observations and current understanding, Atmos. Chem. Phys., 4, 2601-2633, 2004.

Singer, W., Keuer, D., and Eriksen, W.: The ALOMAR MF radar: Technical design and first results, in: Proc. 13th ESA Symp. on European Rocket and Balloon Programmes and Related Research, edited by: Kaldeich-Schürmann, B., ESA SP-397, 101104, 1997.

Stebel, K., Blum, U., Fricke, K.-H., Kirkwood, S., Mitchell, N., and Osepian, A.: Joint radar/lidar observations of possible aerosol layers in the winter mesosphere, J. Atmos. Sol. Terr. Phys., 66(11), 957-970, 2004.

Thrane, E. V. and Grandal, B.: Observations of fine scale structure in the mesosphere and lower thermosphere, J. Atmos. Terr. Phys., 43, 179-189, 1981.

Turunen T., Westman, A., Häggström, I., and Wannberg, G.: High resolution general purpose D-layer experiment for EISCAT incoherent scatter radars using selected set of random codes, Ann. Geophys., 20, 1469-1477, 2002.

Werne, J. and Fritts, D. C.: Stratified shear turbulence: evolution and statistics, Geophys. Res. Lett. 26, 439-442, 1999. 